\title{
El despido injustificado como instituto de control social
}

\author{
Adolfo Nicolás Balbin ${ }^{1}$
}

\section{Introducción}

El Derecho del Trabajo se estructura en base a una serie de principios que le sirven de fundamento y soporte; serían como el esqueleto de un edificio sin el cual la construcción completa caería por debilidad (CORNAGLIA, 2001:7).

En ese entramado, y aun considerando que todos son muy importantes (pues autonomizan a la materia, pero a su vez le dan el puntapié filosófico y el basamento teórico para su continuo crecimiento), es de destacar que el principio de estabilidad es particularmente esencial a la hora de analizar la relación jurídica que une al trabajador con el empleador, los dos protagonistas básicos de la relación de trabajo.

$\mathrm{Y}$ es que la estabilidad, con su carácter eminentemente instrumental, facilita una de las propiedades más importantes con que cuenta el trabajador, uno de sus principales capitales, traducido éste en la propiedad de su puesto de trabajo.

Ahora bien, una cosa son las enunciaciones que podemos hacer desde la teoría y otra -o conjunto de otras- son las que se observan en la realidad, pues el derecho de eso se trata, o de eso parte, de conductas humanas en relación.

Es en esa realidad en donde se estudia la relación de trabajo, calificada más que como un contrato -en donde ambos interesados se conectan jurídicamente sobre bases igualitarias, luciendo a su vez poderes de similar alcance-, como una relación de poder -traducida en la concreción de un poder omnímodo

\footnotetext{
1 Abogado (UNLP). Profesor Adjunto en Derecho Social. Facultad de Ciencias Jurídicas y Sociales, Universidad Nacional de La Plata, Argentina.

Correo electrónico: nicolasbalbin@hotmail.com
} 
en cabeza del empleador, y dirigido sobre todo al trabajador, justificado a su vez por el propio sistema-, dejando a la vista el carácter ambivalente de la disciplina ${ }^{2}$.

La relación de trabajado es entonces desde nuestro punto de vista, una relación de poder que, como tal, de traduce en una vinculación de mando y obediencia, mayormente en beneficio de una de las partes contratantes.

En este entramado (y en lo que interesa especialmente para este trabajo), nos topamos con el instituto del despido injustificado, que vendría a materializar una de las herramientas privilegiadas de propiedad del empleador.

Si bien los apartados siguientes serán los encargados de contener específicamente el tema que ahora nos convoca, lo más interesante en el punto es que ese poder empresarial facilita el dinamismo negativo del tracto apropiativo laboral, al permitirle al empleador controlar la voluntad del trabajador dependiente, fusionando en cierta medida sus intereses con los de la empresa.

Claro que esa fusión es en verdad aparente y tiende, más que a mejorar la situación de la clase obrera, a colocar cada vez más alto el poder de quien aparece en dicha vinculación respaldado por la propiedad de los medios de producción.

Sostenemos la idea de que el despido injustificado sirve para controlar al trabajador, no solo en el momento en que la relación de trabajo se extingue, sino también a lo largo de todo el contrato de trabajo.

En efecto, el trabajador desde el mismo evento de la contratación conoce su precaria situación y, fruto de ello, acepta numerosas veces condiciones de trabajo que escapan a los marcos de legalidad y justicia consagrados por el ordenamiento general estructurado justamente para protegerlos.

Entonces advertimos el sentido instrumental del despido sin justa causa, traducido en un mecanismo de control social en

\footnotetext{
2 Ver nuestro trabajo: "Discusiones en torno a la esencia del vínculo jurídico laboral". Publicado en la Revista Derechos en Acción (ReDeA), edic. invierno 2017, páginas 79 a 95.
} 
cabeza del empleador. El trabajador la mayoría de las veces teme ser despedido, es decir, pretende conservar su puesto de trabajo la mayor cantidad de tiempo que le sea posible, y ese afán lo conduce muchas veces a aceptar leoninas condiciones en el cumplimiento de su prestación, más aún en un contexto de profundo desempleo y expansión de la pobreza, así como también de formas de trabajo no registrado, o con deficiencia de tal carácter.

La presente investigación tiene por objeto pues, brindar una óptica complementaria al estudio del instituto del despido injustificado receptado en el artículo 245 de la LCT, aportando a los elementos típicamente jurídicos, importantes ideas provenientes de la sociología, además de una visión crítica adicional.

\section{La faz legal. Breves líneas sobre la sistemática del artículo 245 de la LCT}

El presente trabajo, como ya se adelantó en la introducción general que precede, se asienta particularmente sobre el instituto consagrado en el artículo 245 de la LCT (Ley de Contrato de Trabajo).

Como ya sabemos, el mismo recepta positivamente la figura del despido injustificado (para algunos también puede ser denominado como incausado, aunque preferimos optar por la primer identificación, ya que en la materialización de esa causal de despido, siempre obra como causa la voluntad del empleador).

Sucintamente, repasamos que el artículo 245 de la LCT faculta al empleador a poner fin a la relación de trabajo en cualquier oportunidad, sin necesidad de tener que invocar causa justificada alguna (o demostrarla), todo con la única obligación de abonarle al trabajador dañado una "indemnización" que, como la propia LCT lo regula en el apartado de cita, se encuentra delineada por dos figuras: la tarifa y el tope (adelantamos que en páginas posteriores, ensayaremos una crítica a esta consecuencia pecuniaria). 
La primera (tarifa), se calcula teniendo en cuenta dos tópicos: antigüedad en el empleo, y remuneración devengada. Y así, como primer elemento a tener en cuenta, debemos considerar una mejor remuneración mensual, normal y habitual, por cada año trabajado ${ }^{3}$, resultado que se deberá multiplicar por cada año de servicio, o fracción que no disminuya de los tres meses.

Pero lo anterior encuentra otro matiz con el segundo límite legal fijado a la indemnización del trabajador, es decir el tope, en tanto el mismo actúa como techo máximo de la base tarifaria. El mismo se calcula considerando el promedio de las remuneraciones fijadas por el convenio colectivo de trabajo aplicable al trabajador y funciona, se reitera, como límite infranqueable a la indemnización por el despido dispuesto unilateralmente de parte del empleador.

Sobre la precedente base positiva general (y sin extendernos demasiado en la referencia a sus matices legales puntuales, que escapan al objeto de este trabajo), bien podríamos decir que el legislador desde la misma sanción de la LCT ha reconocido el carácter ambivalente de la relación jurídica habida entre empleador y trabajador, al habilitar al primero a que en cualquier momento pueda extinguir el denominado contrato de trabajo ${ }^{4}$.

Es decir, el artículo 245 de la LCT consagra un instituto que facilita al empleador anticipar los gastos que le puede irrogar la extinción de una o varias relaciones jurídicas, consagración legislativa que actúa en notable detrimento de los derechos obreros conquistados.

3 En los marcos de la LCT, para que se efectivice el contrato de trabajo no resultará necesaria la permanente ejecución de tareas, sino que en los términos de sus artículos 21 y 103, bastará con la mera puesta a disposición de la fuerza laboral del trabajador en favor del empleador, en tanto el primer artículo de cita habla de una persona que se "obliga a", mientras el segundo prescribe que la remuneración se devenga en favor del trabador "por la mera circunstancia de haber puesto su fuerza de trabajo a disposición de aquel".

4 Para una ampliación respecto al carácter ambivalente del Derecho del Trabajo, se puede consultar (entre otros), nuestro artículo titulado: "El concepto de Derecho del Trabajo", publicado en Revista Anales de la Facultad de Ciencias Jurídicas y Sociales, Universidad Nacional de La Plata, año 12 nro. 45, págs. 359 a 375. 


\section{La faz sociológica. Sistemas de control social}

Fuente reiterada de citas resulta ser el diccionario on line de la Real Academia Española que, en materia de control -simplemente-, lo define de la siguiente manera: Del fr. Contróle. 1. Comprobación, inspección, fiscalización, intervención. 2. Dominio, mando, preponderancia. 3. Oficina, despacho, dependencia, etc, donde se controla. 4. Puesto de control. 5. Regulación manual o automática, sobre un sistema. 6. testigo (muestra). 7. Mando o dispositivo de regulación. 8. Tablero o panel donde se encuentran los mandos. 9. Examen parcial para comprobar la marcha de los alumnos 5 .

De los anteriores conceptos, podemos resaltar elementos comunes. Así, se advierte repetida tres veces la palabra mando, y también se mencionan las palabras regulación, preponderancia, inspección, fiscalización, comprobación (aunque todas estas últimas solamente están referenciadas una sola vez, sin que eso nos haga perder el curso de la idea que se intenta seguir en el presente apartado). A partir de allí, podemos adelantar una teoría: que el control es poder y dominación, a la vez que regulación.

Como surge de líneas supra, ya contamos con una somera idea del control simple y lato, a partir de la cual nos arriesgamos a decir que el concepto de mando y regulación son elementos necesarios (o derivados), de dicha palabra. Mas aquí en rigor de verdad nos proponemos analizar una noción más compleja, la del control social, adelantándose al respecto que sobre ello nos topamos básicamente con dos vertientes interpretativas, una que lo aproxima a la idea de la regulación, y otra que lo vincula más bien con las nociones de coacción y dominación. A continuación haremos una apretada síntesis de ambas posturas.

En la primera escuela, podemos advertir que desde los orígenes de la sociología como disciplina científica, el término del control social constituía un aspecto importante de lo colectivo,

5 Definición disponible on line en el siguiente enlace: http://dle.rae.es/?id=AeYZO9V [fecha de consulta, 14 de febrero de 2018]. 
funcional para el entendimiento del orden social. En los marcos más básicos, el control social estaba referido a la capacidad de la sociedad de regularse a sí misma, acorde con los principios y valores deseados. Así, el análisis sociológico tiene la tarea de explorar las condiciones y variables que hacen a esta meta susceptible de ser alcanzada.

La noción de control social con el sentido que estamos ahora analizando nos viene sobre todo de la sociología norteamericana, asociándosela en la casi generalidad de los casos a la idea de dominación como instrumento positivo. En este sentido, Talcott Parsons traduce la noción de berrschaft (dominación) construída inicialmente por Marx Weber, en imperative control, es decir, transforma el concepto de control en un elemento utilitario y positivo.

Según algunos autores, el interés por el control social hace su aparición en la sociología norteamericana durante la década de 1920, principalmente en dos ámbitos: por un lado, se lo menciona en estudios concernientes a la desviación y a la criminalidad; y por el otro, también surge el mentado concepto a propósito de la asimilación, por los inmigrantes y los miembros de las minorías étnicas, de los modelos norteamericanos impuestos desde la clase media (Boudon y Bourricaud, 1974).

Para esta orientación entonces, el control social no se lleva a cabo a través de una serie de instituciones cerradas (que dio lugar a la exposición de la teoría del panóptico de Michel Foucault -con su base indispensable en J. Bentham-), sino mediante una red de instituciones sociales y políticas descentralizadas y propias del sistema democrático.

Por su parte, en la vereda opuesta (tal como lo adelantamos en el párrafo que antecede), nos encontramos con la visiones que estudian al control social como instrumento de coacción.

En verdad esta es la tesis que nos interesa en este trabajo de investigación, tendiente justamente a analizar el despido como herramienta de control social (y a explicar los motivos del por qué de esa derivación, según entendemos), y como medio de 
coacción del empleador frente al trabajador, desposeído de similares atributos.

Como quedó delineado antes, la perspectiva del control social está asentada en la suposición acerca de las interacciones y las influencias mutuas. Por lo tanto, plantea la cuestión relacionada a las consecuencias del ejercicio de la fuerza y la coerción en beneficio de aquellos que la aplican, ya sea que el objetivo tienda al mantenimiento de una estructura social, o bien a su cambio.

En esto, se entiende que la desintegración social implica una reducción en la capacidad de un grupo para controlar el comportamiento de sus miembros y una declinación de la interacción e influencia; más lo cierto es que los conflictos sociales implican, por contrapartida, un crecimiento de la interacción entre los grupos sociales sobre la base del antagonismo en los significados y en las metas de cada uno (Janovik).

Para algunos, la existencia de elementos coercitivos en el seno de una sociedad implica la presencia de instrumentos de persuasión de la sociedad industrial, "encontrar los medios para guiar la conciencia individual y el deseo de los miembros de una sociedad" (Ross, 1901, citado por Janowitz). Para nosotros, el conflicto parte sobretodo de la idea de desigualdad, jurídica y económica, entre los integrantes de una sociedad y, específicamente en lo que aquí investigamos, de la sociedad laboral, traduciéndose ello en el reconocimiento del poder del empleador para violentar al trabajador, y la casi ausencia mecanismos de defensa para el sujeto débil de tal relación. Un control social micro (aunque puede tener proyecciones macro, como a continuación veremos), pero no por ello menos lesivo a los intereses de la sociedad.

Esa vertiente se ha desenvuelto sobretodo (al menos en cuanto a las incidencias dentro del Derecho del Trabajo) en el sistema económico capitalista, modelo económico criticable pero exitoso en cierto sentido. Este persiste aproximadamente desde finales del siglo XVII, momento de la historia en que la producción pasó a proyectarse no ya como medio de sustento, sino de intercambio sobre todo a gran escala, definiendo de la 
misma manera los efectos de dicho proceso. Ya no se trataba de una economía de sustentación, sino de un proyecto que tendió al incremento de la movilidad de personas, cosas y divisas. Para ello se trató de mecanizar el sistema productivo, lográndose esto con la incorporación al sistema de nuevas y novedosas -para entonces-, maquinarias y técnicas, como lo fueron el telar mecánico o la progresión de los medios de transporte (sobre todo el ferrocarril), aunque desde el discurso oficial se omitió difundir que la mentada mecanización lo sería también en parte, de las personas involucradas en el proceso productivo, de los y las trabajadoras, verdaderos protagonistas de esa triste historia.

Quien ha trabajado profundamente, desde lo clásico, dentro de esta vertiente fue Michel Foucault. El mismo, en obras memorables $^{6}$, ha estudiado el control sobre el cuerpo de las personas (que involucraba al derecho penal, pero por derivación también a los sistemas de control utilizados dentro del modelo laboral capitalista), nutriendo la vertiente que comprende al control, más que como regulación o instrumento de equilibrio social, como mecanismo de sometimiento, adaptando su análisis al entorno evolutivo que conllevó el cambio de una sociedad de castigo, a una sociedad de vigilancia. En el último punto es que tuvo mayor relevancia el estudio de la fábrica como institución de control y, con ella, el derivado panoptismo que dinamizó el éxito del poder disciplinario a través de lo que se conoció como proceso de moralización de los cuerpos.

\section{El derecho y la sociología. Algunas derivaciones. Los poderes exorbitantes del empleador y el artículo 245 LCT}

En los anteriores apartados, hemos hecho mención a dos campos del conocimiento, uno legal, y otro de matriz sociológica. Más este trabajo en realidad está orientado a entrelazar

6 Se recomienda consultar los siguientes libros: "Microfísica del poder" (Madrid: La Piqueta), "Vigilar y Castigar. Nacimiento de la prisión" (Buenos Aires: Siglo XXI editores), así como también "La vida de los hombres infames" (La Plata: Altamira). Todas referenciadas en el apartado de la bibliografía. 
ambas disciplinas, para tratar de comprender ciertos alcances que creemos importantes respecto de un instituto también destacable por sus consecuencias dentro de la LCT. Con tal fin, continuaremos en lo sucesivo unificando los elementos ya vistos en las páginas supra.

Como ya expresamos someramente, entendemos que el vínculo jurídico laboral no se desenvuelve a partir de un contrato, sino en base a una relación jurídica que conecta dos voluntades con objetivos diferentes, pero en un espacio y tiempo común ${ }^{7}$.

Esa idea de la relación de trabajo, se encuadra en una estructura ambivalente que justifica y desarrolla una vinculación desnivelada de poderes y fuerzas sociales, con diferente impacto económico y cultural, pero siempre tendiente a dar prevalencia a la voluntad del empleador.

En el denominado contrato de trabajo, el empleador es dueño no sólo de la empresa -que dirige y organiza-, sino en parte también del propio trabajador, a quien controla -sobre todo con la coerción-, ordena y vigila.

Por empezar, tenemos que tener en cuenta que la relación de trabajo no genera un vínculo de solidaridad ni menos de colaboración. Nada de solidaridad existe en el derecho del trabajo, más allá de los efectos de algunas obligaciones frente al crédito preferente de contenido alimentario, por lo que la regla receptada en la última parte del artículo 62 de la LCT no es sincera ni concreta. Tampoco creemos que sea un ideal, sino un mito. No es una utopía, sino un concepto vacío e ineficaz.

\footnotetext{
7 Entendemos que aunque el empleador no se encuentre cotidianamente en la empresa 0 en el lugar en que el trabajador presta efectivamente tareas, no se deslegitima la idea esbozada, desde que aún en las formas de trabajo virtuales, se viabiliza el poder de control del empleador y su presencia aunque no física si concreta y efectiva. De hecho, la celebración misma del negocio laboral supone la materialización más evidente de la subordinación, característica clave del modelo explicado, a través de la llamada dependencia jurídica, que conlleva la atribución al empleador para poder sustituir la voluntad del trabajador por la suya propia, encorsetando de manera casi permanente la subjetividad de aquel, en beneficio del empresario.
} 
No podemos denominar solidario o de colaboración a un vínculo en que las partes actúan de tal manera contrapuestas, que si no existieran formas modernas de canalización de ese conflicto, no podríamos hablar siquiera de la existencia de una disciplina protectoria.

Aún con la presencia del orden público laboral, u orden público social como se prefiere denominar en el derecho comunitario europeo, la relación de poder sigue siendo dispar en beneficio del empleador, y de nada nos sirve tampoco decir que "el contrato de trabajo tiene como principal objeto la actividad productiva y creadora del hombre en sí (y que) sólo después ha de entenderse que media entre las partes una relación de intercambio y un fin económico en cuanto se disciplina por ésta ley", como reza el segundo párrafo del artículo 4 de la Ley 20.744, sobre todo si en la misma norma tenemos un artículo posterior que defiende la onerosidad del contrato de trabajo en tanto no lo presume gratuito (art. 115 LCT), o la existencia misma de facultades de dominación y control tal como ocurre en el caso del artículo 245 de la LCT.

Pero sin ánimo de reiterar conceptos ya expuestos, nos interesa ahora referirnos más en particular a los denominados poderes exorbitantes del empleador, para lo cual las primeras ideas de este acápite nos sirven de introducción general.

Como se sabe, en la relación laboral tanto el trabajador como el empleador tienen derechos y obligaciones elementales, y otros de contenido complementario. De esa manera, se distingue en doctrina entre las obligaciones de cumplimiento y las de conducta, binomio que en su primer término hace referencia a los deberes principales de cada sujeto -con sus paralelas acreencias-, mientras que las del segundo concepto refieren como se dijo antes de manera general, a determinadas exigencias de contenido más actitudinal pero que, no obstante no configurar elementos centrales o definitorios en la relación laboral, lo matizan de tal modo que su violación podría acarrear un perjuicio atendible jurídica y económicamente. 
Sobre lo anterior, y a fin de clarificar las ideas allí expuestas, las obligaciones de cumplimiento -como deber central o esencial-, involucra al trabajador para poner su fuerza de trabajo a disposición del empleador (aunque éste no haga uso efectivo de la misma, pudiendo hacerlo no obstante), y de parte del empleador exige, paralelamente, el pago de la remuneración y las obligaciones de seguridad, como centrales. A su diestra, campean los deberes de conducta, entre los que podemos citar los de no concurrencia y de fidelidad, de parte del trabajador, y el respeto por la igualdad de trato o el respeto por las invenciones del trabajador, de mano del empleador.

Ahora bien, sin entrar a analizar y criticar cada uno de los derechos o deberes de las partes (lo que excedería en mucho el objeto de este trabajo), remarcamos que en nuestro ordenamiento positivo existen ciertas facultades que desnivelan la solidaridad y colaboración propendidas como norte primero, favoreciendo de manera injustificada a uno de los contratantes en claro perjuicio de su par legal. Aquí es donde entra el tema de las facultades o poderes exorbitantes que la ley sólo le reconoce al empleador. Se reitera, no existen en nuestro derecho nacional poderes o facultades exorbitantes en beneficio de los trabajadores; y si en alguna oportunidad llegasen a existir (dudamos), no faltarían quienes enarbolen desde el primer momento banderas con insignias tendientes a rescatar el desnivel negativo perdido, en relación a nuevos perjuicios causados -potencialmente-, al otro contratante.

El perjuicio de esta situación es que dichos poderes extralimitados tienden por parte de cierto sector de la doctrina a ser naturalizados, o absorbidos, sin hacer ningún tipo de crítica a su respecto. Con eso corremos el riesgo de agrietar la esencia protectoria que tiene esta disciplina, y que no viene dada, es decir no surge de ningún manantial que brote de la tierra, sino que es un concepto para construir y trabajar, para defender y extender desde la academia, desde el trabajo diario de la abogacía liberal, desde la judicatura, desde los puestos legislativos o administrativos, desde la banca política. El dato es 
que cuando no se defiende esa bandera, o se prefiere recorrer el sendero más reducido, la disciplina no crece, sino que tiende a envejecer y deshidratarse; sus contenidos se vuelven vetustos y desactualizados, sobre todo en el amplio panorama actual de nuestro sistema internacional de derechos humanos, por lo que según creemos nuestros aportes deben ser a la inversa: trabajar en un sentido o en otro, pero dando fundamentos a nuestros dichos. Aquí el aporte consiste en criticar la existencia de tales potestades desniveladas del empleador.

Nos parece importante, en este íter, identificar aunque más no sea someramente, los casos más evidentes de poderes exorbitantes con que cuenta el empleador en nuestro derecho nacional. En esa línea, podemos encontrar el poder de variar ciertas condiciones del contrato de trabajo -aunque con ciertos límites legales-, el poder de aplicar sanciones disciplinarias al trabajador y, por sobre todo, el poder de extinguir en cualquier oportunidad a la relación laboral, sin mayores consecuencias que la obligación de pagar una indemnización que a todos evento es de contenido tarifario, es decir, limitado, acotado a los intereses del empleador, sujeto más beneficiado con el instituto receptado en el artículo 245 de la LCT, que le permite anticipar los costos empresariales frente a la efectivización de su voluntad rescisoria ${ }^{8}$.

Pero la paradoja del sistema estriba en que, por un lado, el ordenamiento jurídico atribuye poderes exorbitantes al empleador, mas posteriormente tiende a suavizar ciertos aspectos del mismo (sin aniquilarlos totalmente), otorgándole al trabajador afectado algunos beneficios -o defensas-, por así decirlo secundarios (ejemplo de ello son las alternativas que puede seguir el trabajador ante la materialización abusiva del ius variandi, conforme prescribe el segundo párrafo del art. 66 de la LCT).

8 También a nuestro criterio entrarían dentro de los poderes exorbitantes, los de dirección (art 65 LCT), la posibilidad de efectuar controles de tipo personal (art. 70 LCT), la posibilidad de suspender la relación de trabajo por causas económicas (218 y ss. de la LCT), entre otras. 
Entonces a esta altura podríamos preguntarnos desde qué sentido se puede tildar de exorbitantes a un conjunto de poderes del empleador: desde el mismo sentido de justicia y equidad, desde el serio respecto por la buena fe, y desde el principio de igualdad y no discriminación, enunciados todos como estandartes generales dentro de la propia LCT, aunque luego casi olvidados, dando pié al tópico de la ambivalencia de la materia.

\section{Las materializaciones del control social en el instituto del despido injustificado}

Aquí nos adentramos en el punto elemental de nuestra investigación. Tratar de explicar por qué consideramos que el despido injustificado habilitado por el artículo 245 de la LCT debe ser estudiado como un instrumento de control social en manos de los empleadores y, a la vez, de manera paralela, como concreción de un poder exorbitante de su parte.

Hemos referido hasta este momento a varias instituciones del Derecho del Trabajo y de la sociología vinculada, y tratamos de conectarla en cada momento oportuno con el caso analizado. En los apartados siguientes haremos una profundización de otros elementos importantes que nos ayuden a comprobar nuestra idea inicial.

Entendemos que el despido injustificado es una herramienta de control social en manos del empleador. Se trata de un control social privado, justificado por el propio sistema jurídico habilitante de ese micro poder avasallante de los derechos de los trabajadores. Los justificativos elementales de esa idea proyectada, han sido planteados en una serie de puntos que a continuación serán desarrollados.

\section{No hay derecho a despedir pero igual se despide}

Como dice este sub-título, dentro del despido injustificado -definido por la doctrina como el acto unilateral del empleador mediante el cual éste dispone la resolución del contrato, sin que 
medie un motivo legalmente atendible que legitime esa decisión rupturista (Gatti, 2015:513)-, no existe derecho a despedir.

En la doctrina nacional algunos autores interpretan a -nuestro entender de manera errada-, que existe un derecho subjetivo del empleador a despedir sin causa justificada, disponiéndose además que el empleador puede hacer uso de tal facultad cuando así lo aconseje el giro normal de sus negocios, siempre y cuando cumpla con dos obligaciones: otorgar el preaviso, y pagar en tiempo y forma la indemnización por despido fijada en el artículo 245 de la LCT. En tal posición se encuentra por ejemplo Enrique Herrera ${ }^{9}$, entre otros, y se afirma desde allí que en tanto el sistema legal no impide al empleador poder ejercer con eficacia el despido sin brindar causa justificada, tal facultad encuadra dentro de los derechos con que cuenta el empresario en el marco de sus facultades de organización y dirección.

En la dirección contraria, se afirma que el despido injustificado es un acto ilícito, pero eficaz. Para fundamentar la ilicitud propuesta, se ha afirmado que en el ejercicio de tal poder exorbitante, el empleador viola su obligación legal de mantener el contrato hasta la jubilación del trabajador -o hasta que se consideren cumplidos los recaudos establecidos por la ley para que el trabajador pueda acceder al beneficio de la jubilación ordinaria, todo dentro de la lógica del contrato por tiempo indeterminado-, y que dicha transgresión objetiva tiene como basamento la obligación impuesta al empresario rescisor de abonar al trabajador un suma en concepto de "indemnización" tarifada y legal, desde que, según los principios emanados del derecho de las obligaciones, nadie puede ser sancionado por el ejercicio regular de un derecho.

\footnotetext{
9 Afirma el autor de cita que “...por nuestra parte, no pensamos sin más que todo despido sin invocación de causa resulte un acto ilícito o de incumplimiento contractual, pues las partes no se han obligado a mantener sine die la relación, ni la ley admite un derecho a la estabilidad propia en el empleo, llegando al punto de sostener que en nuestra opinión, el empleador dispone de un derecho subjetivo para resolver sin causa el contrato de trabajo cuando así lo aconseje el normal giro de sus negocios" (Herrera, Enrique, "Extinción del contrato de trabajo", en Vázquez Vialard Antonio -Dir.- "Tratado", T. 5, p. 266/277).
} 
Además de la violación a la regla de la continuidad, receptada en el artículo 10 de la LCT, se atribuye el carácter de ilícito al ejercicio del poder extintivo unilateral e injustificado del empleador, argumentándose en esa vereda que se encontraría vulnerada la garantía constitucional de la protección contra el despido arbitrario, garantía reconocida en el primer párrafo del artículo 14 bis de la CN.

Ahora bien, sin perjuicio de la calificación del despido injustificado como un acto ilícito (que compartimos plenamente), no es menos cierto advertir que incluso la doctrina más progresista en el tema debe admitir que tal carácter va acompañado -en nuestro derecho nacional-, por el de la eficacia de tal decisión.

Como se comentó anteriormente, el empleador tiene el poder de aniquilar en cualquier oportunidad la relación de trabajo, y la calificación de ese acto como ilícito no desmembra su paralela consecuencia -y elemental en este punto-, cual es su habilidad para dar por extinguido aquello que muchos denominan fácilmente como contrato de trabajo, sin reparar en que una herramienta jurígena como el poder de despedir sin justa causa, deshabilita ontológicamente el uso de esa denominación general que no alcanza a configurarse realmente en el universo del trabajo, en donde el prestador de tareas se encuentra permanentemente sometido a una voluntad ajena que limita su libertad, y en donde por ende la igualdad (otro elemento de la figura de los contratos del derecho común, fuente elemental) es también un componente totalmente extraño en lo concreto.

En esta senda, señala el profesor Capón Filas que "(...) la realidad demuestra que el temor al despido y el consiguiente desempleo es un gran disciplinador social. Por ello, cada tanto, un despido, de tal modo que siempre pese sobre los trabajadores la advertencia: "el silencio o la expulsión" que repite intramuros de la empresa el eslogan "nosotros o el caos". Tal vez, ese temor explique que durante la relación el trabajador no reclame sus derechos y acompañe con poco entusiasmo las buelgas, cuando existiesen o no las acompañe" (2014:3). 
Cierto es que en los últimos años, se han efectuado por la doctrina importantes aportes tendientes a deslegitimar el poder extintivo del empleador en las relaciones privadas -incluso en las que no se cualifican por una especialidad inicial del vínculo, como serían las relaciones de trabajo del representante gremial protegido por la tutela sindical, o el caso de la mujer embarazada o que ha dado a luz, entre otros supuestos-, mas aún no se ha desactivado tal energía extintiva. El artículo 245 de la LCT sigue vigente y con él toda una amalgama de poderes paralelos (exorbitantes o no, depende del caso), que por un lado desactivan la calificación como contrato del vínculo laboral y, por el otro, de manera consecuente, desnivelan la distribución de fuerzas en perjuicio del trabajador, cosechando así la ambivalencia del Derecho del Trabajo, y fomentando la violación a su propiedad del puesto de empleo.

En esto, dice el maestro Moisés Meik que un modelo de ordenamiento como el argentino, es un sistema que trasunta "una dosis de violencia sobre la persona del trabajador", quien, por ello, tiene internalizado desde el inicio de su relación y a lo largo de su desarrollo o devenir, la implícita amenaza del despido, que opera, además, como un condicionante perverso de "disciplinamiento" social inadmisible. Esa amenaza de despido opera, también, contra el principio de la irrenunciabilidad de los derechos adquiridos por el trabajador durante el desarrollo de la relación laboral. La inestabilidad en el empleo condiciona la inestabilidad en las condiciones de trabajo.

Y agrega en el mismo sentido que, por esa razón, el trabajador se ve empujado con frecuencia a someterse, durante el desarrollo de la relación laboral, a exigencias empresariales solapadas, para que resigne derechos adquiridos durante el curso de la relación laboral, o a inhibirse de plantear oportunamente las reivindicaciones de mejores derechos o reclamos por incumplimiento, todo por el temor al despido, que puede transformarse -como represalia perversa- en la reacción empresarial si persiste la resistencia o conducta reivindicativa del trabajador. 
De todo lo anterior se deriva entonces que la herramienta del despido injustificado es un acto ilícito, pero eficaz, y que a través de este último componente, el empleador empuña un poder exorbitante (el más poderoso de todos), controlando a los trabajadores a su cargo.

\section{La reparación a que da lugar el despido sin justa causa es reducida y no integral}

El artículo 245 de la LCT se titula "Indemnización por antigüedad o despido". Así se ha identificado desde que la Ley 20.744 vio la luz allá por el año 1974.

Sencillamente diremos por ahora que el mecanismo denominado "indemnizatorio" del artículo en comentario, habilita también la consideración de la herramienta del despido injustificado del empleador como un mecanismo de control social.

Ahora bien, cabríamos preguntarnos cómo opera el mentado control a través de una ecuación económica (y financiera también, sobre todo para el empresario), inserta en el artículo 245 de la LCT.

La respuesta es breve. El temor de los trabajadores, su miedo a ser despedidos, se incrementa desde que se sabe de antemano que la extinción del denominado contrato de trabajo no es seguido por una reparación integral de los daños y perjuicios sufridos con motivo del mismo, y más en un contexto de alto desempleo y recesión económica nacional como ocurre a la época en que la presente investigación se lleva a cabo. Para un mayor entendimiento, iremos desmenuzando cada componente de manera progresiva.

En primer término diremos que el mecanismo denominado indemnizatorio del art. 245 LCT no es tal, sino que la compensación económica de que es acreedor el trabajador a partir del acto de despido sin justa causa es tarifada, es decir, sufre una limitación legal en base a dos componentes, como son los que solemos identificar como de la "doble T": la tarifa y el tope (que antes fueron explicadas rápidamente). 
Para clarificar lo anterior tenemos que considerar el significado de la palabra "indemnización".

El Diccionario de la Real Academia Española poco nos ayuda en esta aventura, pero al menos brinda algunos elementos introductorios. Y así dice que indemnizar es: "Resarcir de un daño o perjuicio, generalmente mediante compensación económica"10.

Adaptando lo anterior, se entenderá que obviamente el daño o perjuicio en el caso es la situación de desempleo en que es colocado el trabajador a partir de la comunicación del despido injustificado, y que la mentada compensación económica es la acreencia consecuente del mismo, que involucra no sólo la liquidación de los rubros devengados a partir de la puesta a disposición de su energía corporal por un cierto período de tiempo (sueldo proporcional, SAC, vacaciones, devengados), sino el adicional que la ley obliga a abonar al empleador que decida extinguir el contrato de trabajo, y que se cuantifica con la misérrima fórmula inserta en el artículo en comentario.

Pero afinando los términos, manifiestan Cazeaux y Trigo Represas que la indemnización tiene un triple carácter. Por un lado, dicen los autores de cita, es un medio indirecto de cumplimiento de la obligación. Por el otro -exponen-, tiene como carácter la subsidiariedad, aclarando que a ella se puede acudir solamente cuando es imposible obtener el cumplimiento de la prestación in natura por el deudor o por un tercero. En tercer orden, señalan que la indemnización del daño tiene, asimismo, un carácter resarcitorio, es decir que mediante ella se persigue la finalidad de reparar el perjuicio ocasionado, pero no la de sancionar o castigar al obligado al pago (1969:213).

En cuanto a la finalidad del instituto, refieren que la indemnización de los daños y perjuicios es la de restablecer el equilibrio que el incumplimiento de la prestación o el daño han alterado, procurando por su intermedio colocar al acreedor

\footnotetext{
10 Versión on line del Diccionario de la Real Academia Española, disponible en el siguiente enlace: http://dle.rae.es/?id=LMrZNIo [fecha de consulta 15 de febrero de 2018].
} 
en igual o semejante situación a la que hubiera tenido de no haberse producido la inejecución o la violación del derecho (Cazeaux-Trigo Represas, 1969:214).

Si bien el mecanismo explicado por los profesores Cazeaux y Trigo Represas se direcciona a las obligaciones civiles, sus conceptos son extensivos al resto del derecho, y entre ese universo obviamente al Derecho del Trabajo, por lo que mal haríamos en no aplicar tales herramientas provenientes del derecho común para entender las obligaciones derivadas de la relación laboral.

En ese entramado, advertimos que lo que se identifica en el artículo 245 de la LCT como "indemnización”, no reúne ninguno de los caracteres centrales que antes se han referenciado. En esa senda, la "indemnización" laboral por despido injustificado mal puede ser considerada como un mecanismo de cumplimiento del contrato laboral desde que, por un lado, se permite que por su intermedio la regla de la continuidad de la relación de trabajo (que el contrato se extienda hasta que el trabajador se encuentre en condiciones de jubilarse) se vea alterado por la sola expresión de la voluntad del empleador y, por el otro, tomando en cuenta las consecuencias tan negativas que tal decisión provoca en el trabajador dependiente. No hay cumplimiento del contrato laboral aunque se abonen las sumas de dinero cuantificadas en el artículo 245 de la LCT, ya que ese mecanismo sólo tiene por objeto prever costos empresariales y no proteger al trabajador, sujeto de especial tutela constitucional según la interpretación vertida por la CSJN en el caso "Vizzoti c/AMSA S.A."11, y según la propia directiva del artículo 14 bis $\mathrm{CN}$.

En un segundo aspecto, la reparación del artículo 245 tampoco es subsidiaria, sino directa. Es decir, no se habilita legalmente a que el trabajador despedido de manera injustificada pueda requerir la anulación del despido y la reposición al estado en que se encontraba con anterioridad al acto rescisorio, salvando los casos de despidos injustificados agravados, y sin perjuicio de la buena doctrina nacional que defiende desde el

11 CSJN, 14/9/2004. 
derecho constitucional e internacional y de derechos humanos la posición contraria. Reiteramos, legalmente no se habilita la restitución in natura, aclarando que cuando decimos legalmente sólo nos referimos al mecanismo del artículo 245 de la LCT que se autodenomina "indemnizatorio" cuando en realidad no lo es, sin menospreciar las posiciones de otros autores que de buena manera (nosotros coincidimos), atacan el despido injustificado, pero desde otras fuentes.

Reiteramos, la solución impuesta por el legislador a través del artículo 245 no es la reparación in natura, sino en especie, a través de una suma limitada o tarifada.

Finalmente, advertimos que tampoco se cumple en la especie con el tercer carácter explicado por Cazeaux y Trigo Represas, cual es el resarcitorio, y volviendo aquí a una frase expresada supra, ambos autores entienden en cuanto a la indemnización que "mediante ella se persigue la finalidad de reparar el perjuicio ocasionado, pero no la de sancionar o castigar al obligado al pago" (1969:213).

Aquí tenemos dos cosas que decir. Por un lado, que la reparación laboral por despido injustificado consagrada en la LCT nuevamente -esta vez por la ausencia del tercer carácter general-, no es indemnización, ya que, volviendo, no tiene la cualidad de ser reparatoria, sino solo compensatoria. Por el otro, y circunscribiéndonos al ámbito exclusivamente laboral, entendemos que la compensación dineraria parcial del artículo 245 tiene como correlato la producción de una daño (el despido sin justa causa de un trabajador), pero también en paralelo la ocasión de una sanción legal aplicada al empleador por haber extinguido el vínculo, de ahí la calificación de acto ilícito, lo que corrobora una vez más a nuestro entender que no estamos en presencia de un derecho subjetivo del empleador a despedir.

En este sentido, ha expresado Juan Orsini que en el caso de marras, la norma jurídica prescribe una conducta determinada, en cuyo marco, se le impone al empleador que decide celebrar de manera voluntaria un contrato de trabajo, el deber jurídico 
de cumplir con todas las obligaciones que se derivan de ese vínculo hasta que el trabajador esté en condiciones de obtener un beneficio jubilatorio. Es decir, ese sería su deber ser. Pero si el empleador no observa de manera espontánea el cumplimiento de la norma, el propio ordenamiento jurídico le impone una sanción, como reacción del derecho contra los actos de conducta humana calificados de ilícitos o contrarios al derecho (2007:657).

Es decir, que la obligación de pagar la compensación económica del art. 245, no nace como correlato del ejercicio de un derecho subjetivo, sino que es una sanción aplicada por el ordenamiento jurídico. Luego, a diferencia de lo planteado por Cazeaux y Trigo Represas, en el caso bajo estudio sí tendríamos que hablar en parte de un castigo al obligado al pago, es decir, al empleador, frente a la acreencia generada en beneficio del trabajador. Por ese motivo Capón Filas no está de acuerdo con identificar la causal de extinción por despido sin justa causa, como despido libre indemnizado, señalando que nadie es sancionado negativamente por ejercer su libertad (2014:3).

En orden a todos los argumentos antes vertidos, entendemos que la suma de dinero que el sistema legal tarifa en el art. 245, de ninguna forma puede ser individualizada como indemnización -a contrario de lo que el título del mismo artículo señala-, sino solamente como una compensación parcial por el daño provocado.

\section{Es un acto de violencia y uno de los mayores poderes exorbitantes del empleador}

Coincidiendo con dos excelentes autores de la literatura jurídico-social europea, Antonio Baylos Grau y Joaquín Perez Rey, y en concordancia con todo lo que hasta este momento llevamos analizado, diremos que el despido debe contemplarse como un fenómeno de violencia inserto en los intinerarios de la autoridad empresarial y que en tanto fenómeno de empresa, más allá de su forma jurídica y de su engarce en el mecanismo regulativo de las relaciones de trabajo entre el momento contractual y el organizativo, es ante todo un acto de violencia del poder privado que se expresa como tal (2009:44). 
Efectivamente, el poder empresarial, aún siendo éste exorbitante como es el caso del despido injustificado, se inserta en un sistema legal y social que en parte lo justifica; se adhiere al mismo, habilitándose que el muro protectorio de las relaciones de trabajo se vea acanalado por facultades desmedidas que dañan a uno de los contratantes. Y como se dijo en páginas anteriores, ese paradigma de violencia no debe encontrar un reducto más de justificación en lo que se dio en llamar como el carácter ambivalente del Derecho del Trabajo, sino que, a contrario, lo útil es construir a partir de allí nuevas herramientas de protección para contrarrestar aquella situación de agresión jurídica y también física en favor de quienes todos los días exponen su persona con motivo de la prestación laboral (manifestación del control sobre los cuerpos).

Como dicen Baylos y Perez Rey -confirmando una vez más la hipótesis del control social que manejamos-, la empresa, a través de la privación del empleo a una persona, procede a expulsarla de una esfera social y culturalmente decisiva, es decir, de una situación compleja en la que a través del trabajo ésta obtiene derechos de integración y de participación en la sociedad, en la cultura, en la educación y en la familia. Crea una persona sin cualidad social, porque la cualidad de la misma y los referentes que le dan seguridad en su vida social dependen del trabajo (2009:44).

Como tuvimos oportunidad de decirlo en otra ocasión ${ }^{12}$, quizá aquello de que el trabajo dignifica tenga algo de cierto, no en cuanto a la dignidad ínsita en todas las personas por el solo hecho de ser tales (que reafirmamos), sino en tanto forma de realización individual y pertenencia grupal.

Prosiguen diciendo Baylos y Perez Rey -derivado de lo anterior-, que el despido es violencia y por eso se expresa a través de formas que la niegan, y que jurídicamente se incluye ese acto rescisorio (o la posibilidad de hacer uso del mismo, es decir, la facultad de despedir sin justificación) en el marco de la relación contractual, y en consecuencia haciéndolo derivar del

12 "El concepto de Derecho del Trabajo", publicado en Revista Anales de la Facultad de Ciencias Jurídicas y Sociales, Universidad Nacional de La Plata, año 12 nro. 45, pág. 374. 
sometimiento voluntario del trabajador y de las dificultades del cumplimiento de lo acordado, diluyéndose entonces el aspecto coactivo del acto de rescisión del contrato en la organización del consentimiento en la producción y los procesos de trabajo, como un elemento implícito de éste (2009:44-45).

Entendemos que esa fuerza es permanente a lo largo de toda la vinculación laboral, y no necesita ser concretada especialmente para comprobar su verdadera presencia, aún cuando puede generar efectos agresivos encumbrados como el caso del despido injustificado.

Creemos que el despido sin justa causa es la máxima expresión de violencia dentro de la empresa, y que se trata de ocultarla -además-, tras la figura del contrato de trabajo, haciendo ver a las partes como libres o iguales cuando en verdad no lo son. Pero también pensamos que la violencia parte de otros casos, como la desigual retribución, las jornadas extenuantes y las magras condiciones de salud, el ejercicio desorbitado del ius variandi, entre otros ejemplos, aún cuando concluimos que todos esos ítems tratan de ser justificados nuevamente por el propio sistema otorgando al empleador las facultades de organización y dirección de la empresa, o creyendo en su esencialidad dentro del llamado contrato de trabajo, o en la legitimidad derivada del ejercicio de algún derecho de propiedad.

Recordemos que los empleadores no son los únicos propietarios dentro de la relación laboral, ya que los trabajadores son titulares de una triple propiedad: propiedad de su cuerpo, del puesto de trabajo, y una propiedad social, y que las mismas también deben ser defendidas.

En parte, como dicen Baylos y Perez Rey, también dentro de esa aparente lógica contractual se intenta ocultar la violencia del despido injustificado tras la configuración de un relato que sólo da cuenta de ciertas consecuencias económicas derivadas de la rescisión del vínculo, aunque desde allí también se controle, sobre todo con una reparación parcial como la derivada del artículo 245 de la LCT que ya hemos analizado páginas atrás. 
Dicen los autores de cita que "el despido pretende situarse en el marco de una conducta puramente económica, la privación de los medios de renta de una persona, para aislar este referente de su repercusión en términos sociales y del acceso a la participación democrática en términos de derechos" (2009:45).

Como dijimos supra, la tarifa legal del sistema argentino también disciplina. Por su carácter limitado y su interpretación amplia en beneficio del empleador (el fallo "Vizzoti" es prueba de ello, en tanto la CSJN allí dijo que el tope era inconstitucional sólo si reducía la base indemnizatoria en más de un 33\%), los trabajadores tienden a evitarla, sometiéndose a las órdenes del empleador aún cuando algunas de ellas puedan ser calificada de arbitrarias, por miedo a perder su empleo, por temor a ser expulsado "a un espacio desertizado -el no trabajo-, en donde se plantea la pesadilla del sin trabajo, es decir, la precariedad como regla de vida, con repercusiones en los vínculos afectivos, familiares y sociales" (Baylos Grau y Pérez Rey, 2009:46).

Luego, las negativas consecuencias derivadas de la economización del despido injustificado, no sólo surgen antes de materializada la rescisión del contrato por ese motivo -provocando el disciplinamiento del trabajador, y el sometimiento a condiciones que muchas veces le son perjudiciales-, sino que también se pueden advertir luego de efectivizado el acto de violencia del despido sin justica causa, desde que la supuesta reparación en beneficio del trabajador es sólo parcial, y como dijimos en páginas anteriores, no reúne las típicas características de las indemnizaciones del derecho común, a menos que se quiera crear en el Derecho Social una teoría especial de las obligaciones, contraria a los marcos generales que nos vienen dados desde el derecho romano, y que se expresan hoy de manera moderna en nuestro nuevo Código Civil y Comercial.

Entonces el mayor disciplinamiento opera desde que se sabe de antemano, no sólo que la reparación económica derivada del despido injustificado es parcial y no se reproduce, tendiendo a licuarse al corto plazo (el "precio de despido"), sino que además, de provocarse el despido, vamos a sufrir un 
proceso de des-identificación con el grupo económicamente activo, pasando a formar parte de un gran desierto de desempleados en busca de ocupación, incursionando en eso que Baylos y Perez Rey identificaron como "la pesadilla del sin trabajo", agravada en buena manera por contextos de flexibilización laboral y crisis económica.

Coincidiendo una vez más con Baylos y Perez Rey, el despido injustificado es entonces un acto de fuerza que se inscribe en los intinerarios del ejercicio de la autoridad en los lugares de la producción, y al que prestan su potencia la dogmática contractual y su equivalente dinerario.

\section{Ideas finales del despido injustificado como instrumento de control social}

Sobre todo lo trabajado en esta investigación, destacamos nuestra idea expuesta al comienzo, tendiente a desarrollar la faceta del control social que emana a través del instituto del despido injustificado en cabeza del empleador.

El Derecho del Trabajo habilita una herramienta de coerción con contornos tan criticables como los que surgen del artículo 245 de la LCT. De ahí su carácter ambivalente.

Como antes lo pusimos de manifiesto, de las dos posturas del control social, seleccionamos la tesis del conflicto, por entender que sobre esas arenas campea de manera permanente un tipo especial de vinculación para algunos denominada contrato de trabajo, más ha quedado claro nuestra postura tendiente a dar prevalencia a la tesis relacionista.

Emile Durkheim en materia de control trabajó sobre la idea de la denominada conscience collective que constreñía a los hombres (con una fuerza directamente proporcional a la intensidad de la interacción en torno a sus representantes específicas) a comportarse de determinadas maneras, por encima de los intereses egoístas de cada uno de ellos. Esas ideas resultan trasladables a nuestro caso, pero aclarando que en materia laboral, tal conciencia colectiva tiende más a limitar la 
conducta del trabajador que a lograr la pacificación general y el funcionamiento de una sociedad (tesis de la regulación).

En efecto, si bien Ross remarcó que la existencia de elementos coercitivos en el seno de una sociedad implicaba la presencia de instrumentos de persuasión de la sociedad industrial (orientados a construir los medios para guiar la conciencia individual y el deseo de los miembros de una sociedad), lo cierto es que más que persuasión, dentro de una sociedad capitalista como la nuestra, se desenvuelven elementos de imposición permanente que se reproducen, o tienden a ello, y que no se dirigen necesariamente a la canalización de conflictos, sino que muchas veces son fuente de ellos, sobre todo a partir de la desigual distribución de la riqueza resultante del modelo contemporáneo.

En el anterior marco, entendemos que el despido injustificado desequilibra aún más la aparente igualdad contractual, desde que le otorga al empleador el poder de extinguir en cualquier oportunidad el contrato de trabajo, violentando sistemáticamente las tres propiedades fundamentales con que cuenta el trabajador: su puesto de trabajo, su propiedad social y su cuerpo.

$\mathrm{Y}$ es que un sistema de inestabilidad no crea más que situaciones de violencia contra la persona del trabajador, pues cuando se sabe de antemano que el vínculo jurídico laboral al que se está sujeto no es perpetuo (y muchas veces ni siquiera duradero), y aún menos igual, sino que a contrario se encuentra sometido de manera permanente a una de las voluntades pactantes, necesariamente eso tiene por consecuencia la retracción de la voluntad del prestador del trabajo, constriñéndoselo aún en contra de sus propios intereses.

El trabajador hoy día puede llegar a doblegar la voluntad extintiva manifestada por el empleador en ciertos casos especiales como en materia de despido discriminatorio o atentatorio de derechos fundamentales, más la realidad indica que sobre los despidos injustificados simples -es decir, no agravados-, el empresario sigue siendo el protagonista estelar, aun cuando nuestra Constitución Nacional intente desde el año 1957 invertir la balanza de la justicia al proteger al obrero frente al despido injustificado. 
Entonces creemos a esta altura de la investigación que si bien existe un actual problema jurídico -pues el artículo 245 de la LCT sigue aún vigente-, estamos en presencia más que nada de un problema de tipo político, sin que se adviertan al día de la fecha serios intentos legislativos de modificar ese oscuro panorama en materia de extinción del contrato de trabajo.

Bregamos para que el mensaje emanado de este trabajo, antes que una mera reproducción, tienda a la producción de nuevos aportes que traten no sólo de entender una realidad conflictiva, sino también a mejorarla. Una visión prometedora debe prevalecer, aun cuando en ocasiones el contexto legislativo especial lleve consigo un mensaje diferente. En todo caso la reflexión y la lucha por el derecho, como siempre, debe primar por sobre las miradas pesimistas del fenómeno jurídico.

\section{Bibliografía básica consultada}

Ackerman, Mario, y Sudera, Alejandro (2008). "Extinción de la relación laboral". Buenos Aires: Rubinzal Culzoni Editores.

Balbín, Adolfo Nicolás (2015). "El concepto de Derecho del Trabajo", publicado en Revista Anales de la Facultad de Ciencias Jurídicas y Sociales, Universidad Nacional de La Plata, año 12 nro. 45.

Balbín, Adolfo Nicolás (2017). "Discusiones en torno a la esencia del vínculo jurídico laboral". Publicado en la Revista Derechos en Acción (ReDeA), edic. invierno, páginas 79 a 95.

Baylos Grau, A. y Perez Rey, J. (2009). "El despido o la violencia del poder privado". Madrid: Edit. Trotta.

Bidart Campos, Germán J. (1981). "Principios constitucionales de derecho del trabajo (individual y colectivo) y de la seguridad social en el art. 14 bis". Publicado en Revista Trabajo y Seguridad Social, Año 1981, T VIII A.

Boudon, R. y Bourricaud, F. (1974). Diccionario crítico de sociología.

Capón Filas, Enrique (2001). "Protección contra el despido arbitrario - breves apuntes para un debate. Publicado en Revista La 
Causa Laboral, Asociación de Abogados Laboralistas, Año 1; $\mathrm{N}^{\circ}$ 1, Buenos Aires, Octubre de 2001.

Capón Filas, Enrique (2014)."Nulidad del despido sin causa". Publicado en Revista de Derecho del Trabajo nro 7. Extinción del contrato de trabajo. Buenos Aires: Ediciones infojus. Ministerio de Justicia y Derechos Humanos.

Cazeaux y Trigo Represas (1969). "Derecho de las obligaciones". Tomo I. La Plata: Editora platense.

Cornaglia, Ricardo J. (2001), "Reforma Laboral, Análisis Crítico. Aportes para una Teoría General del Derecho del Trabajo en la Crisis”. Buenos Aires: La Ley.

Fernández Madrid, Juan Carlos:(1989). “Tratado Práctico de Derecho del Trabajo", Tomo I. Buenos Aires: La Ley.

Foucault, Michel (1992). "Microfísica del poder". Tercera edición. Madrid: La Piqueta.

Foucault, Michel (2004). "Vigilar y Castigar. Nacimiento de la prisión". Buenos Aires: Siglo XXI editores.

Gatti, Ángel E. (2015) "Derecho del Trabajo. Manual de las relaciones individuales". Buenos Aires: Ediciones B de F.

Janowitz, Morris (1995). "Teoría social y control social". American Journal of Sociology. Vol 81, 1. Universidad de Chicago.

Krotoschin, Ernesto. (1955) "Tratado de Derecho del Trabajo", Buenos Aires: Depalma.

Lopez, Justo (1969). “¿Es inconstitucional el derecho a la estabilidad?". Publicado en Revista Legislación del Trabajo, T XVII A (enero/junio). Buenos Aires: Ed. Contabilidad Moderna.

Lopez, Justo (1973). "Despido arbitrario y estabilidad". Publicado en Revista Legislación del Trabajo, Volumen 21. Buenos Aires: Ed. Contabilidad Moderna.

Meik, Moisés (2003. Inédito). Estudio de doctorado en Economía Industrial y Relaciones Laborales. "La protección contra el despido injustificado en España como derecho al trabajo con estabilidad". (Master). Universidad de Castilla-La Mancha, Campus Albacete.

Melossi, Darío (1992). "El Estado del control social". Madrid: Siglo XXI. Orsini, Juan Ignacio (2007). "Los derechos humanos a la igualdad y a la estabilidad en el empleo como límites infranqueables a la 
eficacia extintiva de los despidos discriminatorios". En Revista La Causa Laboral, $\mathrm{N}^{\mathrm{o}} 31$, mes de diciembre.

Perez Rey, Joaquín (2004). "Estabilidad en el empleo". Edit. Totta SA: Madrid.

Pits, Jesse y Etzioni, Amitai (1974). "Control social".

ROCCA, Ival (1974). "Contrato de trabajo. Ley 20.744". Buenos Aires: Blas editora.

Vazquez Vialard, Antonio (1982). "Tratado de Derecho del Trabajo". Buenos Aires: Editorial Astrea. 